\title{
Desafios Enfrentados por Estudantes de um Curso Técnico a Distância Frente à Pandemia COVID-19
}

\section{Nuvea Kuhn ${ }^{1 *}$}

Luis Felipe Dias Lopes ${ }^{1}$

${ }^{1}$ Universidade Federal de Santa MariaRoraima n 1000- Bairro Camobi Santa Maria, RS - Brasil. nuveak@gmail.com

\section{Resumo}

O presente artigo tem como finalidade identificar os principais desafios enfrentados por estudantes de um curso técnico a distância frente à pandemia COVID-19 no acesso ao curso/disciplinas. Assim, pela emissão de relatórios de acesso no Moodle, verificou-se uma queda significativa de participação dos estudantes no Ambiente Virtual de Aprendizagem (AVA), considerando-se as semanas subsequentes à suspensão das atividades presenciais, conforme determinação do Ministério da Educação (MEC). O curso é ofertado por uma instituição pública federal de ensino, em dois polos de apoio presencial em municípios localizados na região noroeste do estado do Rio Grande do Sul (RS). Além dos relatórios, realizou-se a aplicação de um questionário estruturado a 132 estudantes do curso. Os resultados demonstraram que o distanciamento social e a suspensão das atividades presenciais têm influenciado de forma substancial na dinâmica de estudo e dedicação ao curso. Aspectos como desemprego, não possuir computador e acesso à internet, bem como o fechamento do polo de apoio presencial, mostraram-se fatores determinantes na queda de acessos. Assim, 86,4\% (polo 1) e 84,8\% (polo 2) dos estudantes estão sentindo a influência direta da COVID-19 em seu desempenho escolar.

Palavras-chave: Distanciamento social. Desempenho escolar. Vírus.
COMO CITAR ESTE ARTIGO

ABNT: KUHN, N.; LOPES, L. F. D. Desafios Enfrentados por Estudantes de um Curso Técnico a Distância Frente à Pandemia COVID-19. EaD em Foco, v. 10, n. 3, e1018, 2020. DOI: https://doi.org/10.18264/eadf.v10i3.1018
Recebido 17/ 04/ 2020

Aceito 18/ 08/ 2020

Publicado 24/ 08/ 2020 


\title{
Challenges Faced by Technical Course Students Due to the Distance During the COVID-19 Pandemic
}

\begin{abstract}
This article has the objective to identify the main challenges faced by technical course students due to the distance while accessing the course and disciplines during the coronavirus pandemic. Thus, according to access reports in Moodle, there was a considerable decrease of student's participation in the Virtual Learning Environment (VLE), considering the following weeks after suspending in person activities as determined by the Ministry of Education (MEC). The course is offered by a federal public educational institution, in two on-site support centers in municipalities located in the northwest region of the state of Rio Grande do $\mathrm{Sul}$ (RS). In addition to the reports, a structured questionnaire was applied to 132 students of the course. The results have showed that social distancing and suspension of face-to-face activities have substantially influenced the dynamics of study and dedication to the course. Aspects such as unemployment, not having a computer and internet access, as well as closing the face-to-face support area have proved to be determining factors in the decrease of accesses. Therefore, $86.4 \%$ (Centre 1) and $84.8 \%$ (Centre 2) are the percentage of students who are feeling the direct influence of coronavirus on their school performance.
\end{abstract}

Keywords: Social distancing. School performance. Virus.

\section{Introdução}

A pandemia COVID-19, causada pelo vírus SARS-CoV-2 (FREITAS; NAPIMOGA; DONALISIO, 2020), espaIhou-se rapidamente por diversos países (CROKIDAKIS, 2020, p.1). Especificamente no Brasil, direcionou a uma constante mudança na rotina das pessoas, especialmente no setor educacional.

Para evitar a aglomeração de pessoas e o contágio, ações estão sendo feitas com o intuito de distanciamento social, conforme exigências da Portaria N ${ }^{\circ} .54$, de $1^{\circ}$ de abril de 2020 (MINISTÉRIO DA CIDADANIA, 2020).

Nas instituições de ensino brasileiras, por intermédio de orientações do Ministério da Educação (MEC), sob a Portaria Nº. 343, de 17 de março de 2020 (MEC, 2020a), e Portaria No. 345, de 19 de março de 2020 (MEC, 2020b), as aulas passaram a ocorrer apenas por meios digitais. Assim, uma nova normalidade passou a fazer parte da rotina de professores e estudantes.

Com o advento de casos de COVID-19 no Brasil (CROKIDAKIS, 2020), a dinâmica de encontros presenciais nos cursos a distância também sofreu alterações, por meio da suspensão das atividades desenvolvidas pelos polos de apoio presencial. Essas medidas visam assegurar a segurança e a saúde de estudantes, tutores, professores e demais profissionais envolvidos nas atividades (MINISTÉRIO DA CIDADANIA, 2020).

A partir de fevereiro de 2019, uma instituição pública federal de ensino, localizada na região noroeste no estado do Rio Grande do Sul (RS), passou a ofertar de forma institucionalizada e gratuita 100 vagas anuais para um Curso Técnico a distância, sendo 50 vagas por polo. O curso possui uma carga horária total de 1.000 horas distribuídas ao longo de três semestres. Atualmente, o curso conta com 170 estudantes, contabilizando-se os primeiros e terceiros semestres vigentes. 
Mediante o atendimento às determinações da Instrução Normativa N03/2018, a oferta de vagas para o curso deve acontecer especificamente por um dos campi do Instituto Federal, que passa a atuar como um polo, e por outro pólo, que deve estar prioritariamente localizado em um município próximo. Para este último, a responsabilidade pela infraestrutura, bem como o subsídio de tutores, coordenadores, recursos necessários ao funcionamento do polo, ficam sob responsabilidade da prefeitura. Assim, a relação de parceira entre campus e município (polo) acontece via convênio, por um Termo de Cooperação.

No estudo em questão, um dos campi atua como polo de apoio presencial. Os encontros presenciais com professores e aulas são agendados previamente, e é disponibilizado aos estudantes um cronograma prévio de organização de provas e atividades.

A instituição conta com três laboratórios de informática, possui biblioteca e tem infraestrutura adequada para atendimento desses estudantes. O segundo polo atua mediante Acordo de Cooperação Técnica, realizado entre a prefeitura e a instituição. O polo possui uma infraestrutura adequada. Conta com um laboratório de informática, e o trabalho de auxílio aos estudantes é desenvolvido por duas tutoras.

Apesar de o curso técnico em questão ser a distância e gratuito, os estudantes precisam cumprir uma carga horária presencial em seu polo, seja pela realização de atividades avaliativas, práticas profissionais integradas (PPI's), dentre outros tipos de atividades especificadas no Projeto Pedagógico de Curso (PPC). Essas especificidades visam atender à Resolução № . 6, de 20 de setembro de 2012, que dispõe, em seu Art. 33, sobre a obrigatoriedade em cumprir um mínimo de $20 \%$ (vinte por cento) de carga horária de forma presencial para os cursos técnicos a distância (MEC, 2012). As aulas acontecem pelo software gratuito Moodle, e os conteúdos são disponibilizados semanalmente pelo ambiente virtual de aprendizagem (AVA), de acordo com a programação específica de cada professor em sua respectiva disciplina. A problemática envolvendo este estudo teve início a partir da emissão de relatórios de acesso no Moodle, onde constatou-se uma queda na participação e acessibilidade por parte dos estudantes, especialmente a partir da suspensão das atividades presenciais e do fechamento dos polos de apoio presencial. Assim, buscou-se diagnosticar os principais motivos inerentes ao baixo número de acessos e à baixa participação nas disciplinas.

A situação atual frente à pandemia COVID-19 direcionou a um momento em que as pessoas encontram-se fragilizadas frente ao constante medo de desemprego, contrair ao vírus, estresse, tensão e insegurança (SPONCHIATO, 2020), o que repercute em diversos aspectos de sua vida, tanto no âmbito pessoal, profissional, quanto no desempenho escolar.

Estudar na modalidade a distância envolve inúmeros desafios, que permeiam a conciliação de trabalho, família e estudos e que, por vezes, direcionam à evasão escolar (LACERDA; ESPÍNDOLA, 2013, SANTOS; GIRAFFA, 2016). Assim, por vezes, a decisão em permanecer ou não no curso depende tanto de fatores de ordem intrínseca quanto extrínseca (LACERDA; ESPÍNDOLA, 2013).

Frente a esta realidade, no presente estudo, pretende-se responder à seguinte problemática: que desafios estão sendo enfrentados por estudantes de um curso técnico a distância frente à pandemia COVID-19 no acesso ao curso e disciplinas? Para tanto, possui como objetivo identificar os principais desafios enfrentados por estudantes de um curso técnico a distância frente à pandemia COVID-19 no acesso ao curso e disciplinas. 


\section{Referencial Teórico}

\subsection{Funcionalidades do Moodle}

No AVA, a sala de aula presencial é substituída por uma virtual, onde são estimuladas de forma constante a interação e a participação dos estudantes por meio de diversas ferramentas disponíveis (FARIAS; DIAS, 2010). Assim, pelo AVA, no Moodle, existem diversas possibilidades de comunicação e de recursos didáticos, tais como o fórum de discussão, enquete, envio de tarefas, envio de mensagens, e chat (bate-papo). Esses recursos disponíveis permitem a constante interação entre professores, estudantes e tutores, e propicia dinamicidade na comunicação entre eles (CARNEIRO, 2009, TENÓRIO et al.,2014).

Pelo uso do fórum, pode-se estimular, por exemplo, discussões de ideias e temáticas; já pelo chat (bate-papo), os participantes precisam estar conectados no mesmo momento para discussão. Além do mais, pela ferramenta "recursos", existe a possibilidade de inserção de atividades, materiais, vídeos, tarefas e glossários por parte dos professores, o que auxilia no gerenciamento individual e na configuração de cada disciplina (CARNEIRO, 2009).

Além das ferramentas didáticas voltadas aos estudantes, o Moodle apresenta diversas funcionalidades gerenciais que permitem acompanhar e quantificar, por meio de relatórios, os níveis de participação, a entrega de tarefas, dentre outros elementos pertinentes à interação do estudante no AVA (SILVA, 2011, TENÓRIO; RODRIGUES; TENÓRIO, 2016).

Por meio desta funcionalidade, é possível extrair os seguintes tipos de relatório: relatório de acesso (logs); relatório de logs ativos; relatório de atividades do curso; participação em atividade; conclusão de atividades e notas (CLARO, 2014).

Quando a emissão de relatórios é feita de forma constante, torna-se possível mapear o comportamento do estudante, realizar o acompanhamento da situação atual e, a partir destas informações, planejar estratégias voltadas a evitar a evasão escolar, tão comum nesta modalidade de ensino, de forma a buscar a retenção desses estudantes. Pela perspectiva de Silva (2011, p. 20), “é inegável a importância do uso de relatórios no acompanhamento da dinâmica do processo ensino-aprendizagem, uma vez que estes contribuem de modo significativo para a tomada de decisão no momento da avaliação da aprendizagem".

Diante destes argumentos, percebe-se que estas ferramentas possibilitam direcionar e aprimorar as metodologias utilizadas por parte de professores, bem como direcionar o processo decisório de coordenadores e tutores em estratégias pedagógicas voltadas à aprendizagem e ao comprometimento dos estudantes.

\subsection{Principais características em cursos a distância}

A evasão escolar é uma realidade para muitos cursos a distância (UMEKAWA, 2014, SANTOS; GIRAFFA, 2016). Dentre os principais motivos que direcionam à evasão, destacam-se problemas pessoais, dificuldades em conciliar trabalho e curso, dificuldade de adaptação à metodologia proposta pelo curso, incompatibilidade com o curso, entre outros inúmeros fatores (LACERDA; ESPÍNDOLA, 2013).

Thiago, Carvalho e Trigueiro (2020) elencaram alguns elementos que desencadearam a evasão escolar para estudantes de vários polos em um curso de bacharelado ofertado pela Universidade Aberta do Brasil (UAB) no estado do Mato Grosso (MT), destacando, entre os principais problemas, questões pertinentes à logística entre polo e residência dos estudantes, falta de comunicação entre estudantes e tutores, dificuldade em conciliar trabalho, estudos e família, realização de outro curso, mudança para outro município e falta de auxílio de colegas na turma. Além do mais, questões como dificuldade de acesso à internet e AVA também foram mencionadas. 
Outro elemento desafiador nos cursos a distância é a exclusão digital. Informações do Instituto Brasileiro de Geografia e Estatística (IBGE) referentes ao ano de 2018 demonstraram que apenas 70\% da população brasileira possui acesso à internet (ABRANET, 2019). Neste sentido, Thiago, Carvalho e Trigueiro (2020) argumentaram que a exclusão digital acaba por dificultar a comunicação e a interação entre estudantes, professores e tutores no AVA, visto que esta modalidade de cursos acontece com base na utilização de recursos tecnológicos, e isto inclui prioritariamente ter acesso à internet. Assim, emerge uma realidade desafiadora a ser enfrentada pelos estudantes nos cursos a distância (FARIAS; DIAS, 2010).

Além da evasão escolar e da exclusão digital, outro fator preocupante é o desempenho do estudante e sua dedicação ao curso. Cavalcante e Santos Jr.(2013, p.30) apontaram que, dentre os principais fatores inerentes ao desempenho escolar, estão implícitos elementos que variam de infraestrutura (biblioteca, coordenação de curso e tutoria) ao corpo docente (metodologia de ensino e métodos de avaliação). Para os autores em questão, conhecer o desempenho do estudante possibilita melhorar as práticas didáticas e metodologia por parte do professor.

Assim como existem diversos fatores que direcionam a permanência nos cursos a distância, como a constante interação de tutores (FARIAS; DIAS, 2010), infraestrutura, equipe e processos relacionadas ao polo de apoio presencial (XAVIER, 2016), existem aqueles que direcionam à evasão, principalmente nos primeiros semestres do curso, por motivos variados, como problemas pessoais, dificuldade em conciliar trabalho e curso, dificuldade de adaptação ao curso, dificuldades em matérias específicas, e críticas à estrutura do curso (LACERDA; ESPÍNDOLA, 2013). Neste sentido, ressalta-se ainda a própria relação entre professor e estudante mediada pelos meios tecnológicos e pela distância físico/geográfica existente (XAVIER, 2016).

A gestão de um curso a distância deve possuir o mesmo suporte que o de um presencial, e que possibilite os mesmos serviços oferecidos aos demais, como serviços da secretaria, matrícula, entre outros (XAVIER, 2016). Desta forma, Farias e Dias (2010, p.19) argumentaram que "por se caracterizar como um sistema tecnológico, há de se perceber que as ferramentas apresentadas devem propiciar ao aluno recursos didáticos e de apoio necessários ao seu desenvolvimento".

A pesquisa realizada por Santos e Giraffa (2016), na cidade de Porto Alegre (RS), com 86 alunos de vários cursos de graduação, demonstrou que fatores como qualidade do curso, práticas docentes e dedicação do estudante são fatores decisivos para sua permanência no curso.

Souza (2015) analisou a importância dos polos de apoio presencial para dez egressos do curso de Pedagogia, ofertado pela UAB em São Luís no Maranhão (MA). Assim, demonstrou que os polos são essenciais, principalmente no suporte para estudantes que não possuem computador nem acesso à internet para realizar suas atividades, visto que possibilita toda uma infraestrutura física e humana para subsidiar tais demandas.

O objetivo de fomentar aos polos vislumbra-se a partir da disponibilização de espaços físicos de apoio presencial aos alunos da sua região, mantendo as instalações físicas necessárias para atender aos alunos em questões tecnológicas, de laboratório, de biblioteca, entre outras (SOUZA, 2015, p.3).

No que tange à funcionalidade do polo, Xavier (2016) realizou sua pesquisa em Rezende, no Rio de Janeiro, com o intuito de descrever os fatores estruturais do polo de apoio presencial e a atuação do gestor do polo neste sentido. O polo funciona mediante parceria com a UAB e possui uma infraestrutura e recursos adequados para o atendimento às demandas de estudantes. O funcionamento ocorre mediante cooperação técnica com a Prefeitura Municipal, onde são disponibilizados 18 funcionários para o atendimento ininterrupto dos estudantes. Como o funcionamento dá-se mediante cooperação técnica, os tutores são contratados por meio de processo seletivo realizado pelo município. 
Além do polo, faz-se essencial a atuação do tutor no suporte às demandas dos estudantes por meio do acompanhamento constante, principalmente no que concerne à frequência, desempenho e rendimento (TENÓRIO; RODRIGUES; TENÓRIO, 2016). Assim, percebe-se que vários elementos permeiam a operacionalidade e efetividade de um curso a distância, que dizem respeito tanto a questões de infraestrutura quanto a questões de dedicação por parte dos estudantes.

\section{Metodologia}

A partir da análise aos relatórios de acesso às disciplinas emitido pelo Moodle, pertinente aos primeiro e terceiro semestres dos dois polos participantes, considerando-se como datas de análise de 23 de março até 06 de abril de 2020, identificou-se uma queda substancial de acessos nas semanas seguintes à suspensão de atividades presenciais (17 de março).

À vista disso, para fins de diagnosticar os principais desafios e motivos pelos quais os estudantes do curso técnico a distância deixaram de acessar e participar do curso, elaborou-se um questionário pela ferramenta Google Forms, cujo link foi enviado às tutoras para envio posterior aos estudantes dos dois polos de apoio presenciais. O questionário estruturado foi aplicado do dia 6 a 8 de abril de 2020, contendo questões fechadas.

Assim, por meio de uma abordagem quantitativa, cujo intuito é quantificar dados (ESTRELA, 2018), e descritiva, pois possui "como objetivo a descrição das características de determinada população ou fenômeno" (GIL, 2018, p.24), buscou-se identificar os fatores determinantes que direcionaram à queda de acessos no AVA por parte dos estudantes.

Participaram deste estudo estudantes de dois polos presenciais de um curso a distância ofertado por uma instituição pública federal de ensino, em municípios localizados na região noroeste do RS. Contabilizando os estudantes dos dois polos de apoio presencial, entre primeiros e terceiros semestres ativos, totaliza-se uma população de 170 estudantes. O estudo contou com a participação de uma amostra de 132 estudantes, sendo 66 de cada um dos polos.

Para fins de atentar aos aspectos éticos, optou-se pela utilização de nomes fictícios: polo presencial 1 e polo presencial 2 .

\section{Resultados e Discussões}

\subsection{Perfil dos estudantes}

Os cursos a distância remetem a uma dinamicidade diferente dos cursos presenciais, por meio da flexibilidade propiciada pela autonomia, aprendizagem individual e coletiva do estudante por meio dos recursos tecnológicos (FARIAS; DIAS, 2010). O estudo contou com a participação de 132 estudantes, sendo 66 estudantes do polo presencial 1, destes, 65,2\% estão cursando o primeiro semestre e 34,8\% estão no terceiro semestre.

Para estudar a distância, é preciso possuir as ferramentas mínimas que garantam o acesso ao curso e o acompanhamento adequado às atividades propostas, o que inclui possuir computador e acesso à internet; no entanto, sabe-se que nacionalmente esta é uma realidade distante para uma parcela significativa da população. Quanto a este aspecto, verificou-se que 7,6\% não possuem computador/notebook próprio, e 3\% não possuem acesso à internet, o que impossibilita, por vezes, seu acesso ao curso e às disciplinas, sendo que $74,2 \%$ estão trabalhando atualmente e $25,8 \%$ encontram-se em situação de desemprego. 
Já no que tange ao polo presencial 2, contou com a participação de $60,6 \%$ de estudantes cursando o primeiro semestre, e $39,4 \%$ no terceiro semestre, sendo que $28,8 \%$ não possuem computador/notebook próprio e 16,7\% não possuem acesso à internet.

No quadro atual, a exclusão digital ainda se faz presente na vida de muitas pessoas (FARIAS; DIAS, 2010). No Brasil, estima-se que, no ano de 2018, 30\% da população não possuía acesso à internet (ABRANET, 2019).

Os resultados corroboram com a realidade brasileira, demonstrada por Farias e Dias (2010) e Thiago, Carvalho e Trigueiro (2020), que remete à exclusão digital nos cursos a distância e aos dados apontados pelo IBGE no ano de 2018, que demonstrou que o acesso à internet ainda se faz distante para um percentual significativo da população (ABRANET, 2019).

Assim, um percentual significativo de estudantes, principalmente do polo presencial 2, não possui as ferramentas necessárias para acessar o curso, o que causa uma maior dependência dos mesmos ao auxílio de tutores e de seu deslocamento para contar com a infraestrutura disponível pelo polo de apoio presencial. Em virtude de os polos estarem fechados, muitos estudantes encontram-se sem ter como acessar o curso.

Além do mais, evidenciaram-se altos índices de desemprego, onde $84,8 \%$ dos estudantes encontram-se empregados e 15,2\% encontram-se em situação de desemprego. Diante das dificuldades de acesso ao curso devido ao desemprego e outros fatores supracitados, este momento remete cautela e compreensão por parte de professores e coordenação, mediante a situação em que muitos estudantes se encontram, levando-se em consideração que grande parte da população encontra-se tensa e com medo.

Os dados demonstraram a vulnerabilidade econômica e social enfrentada por muitos estudantes, entrelaçando-se à exclusão digital. No mais, averiguou-se um direcionamento gradativo à evasão escolar. Assim, faz-se necessário entender os principais desafios enfrentados por parte destes estudantes neste momento atípico e que remete a uma nova normalidade, enquanto perdurar a situação de pandemia e distanciamento social.

\subsection{Principais desafios enfrentados}

Estudar a distância exige autonomia, automotivação e autodisciplina (PALLOF; PRATT, 2004, FARIAS; DIAS, 2010), e saber gerenciar de forma individual o tempo necessário e adequado para realizar as atividades propostas pelo curso. Assim, destaca-se a atuação individual e constante, e a compreensão, mesmo que mínima, sobre o uso de recursos tecnológicos e sua operacionalidade aos recursos disponibilizados no AVA (SOUZA, 2015, THIAGO; CARVALHO; TRIGUEIRO, 2020).

Para fins de organização didática do curso, as disciplinas são disponibilizadas semanalmente em dias específicos, para evitar o acúmulo de atividades e conteúdos, de forma a possibilitar uma melhor organização de estudos por parte dos estudantes.

A maioria dos estudantes do polo 1 alegou acessar o curso e disciplinas mais de três vezes por semana, 37,9\%; 34,9\% de duas a três vezes por semana; $24,2 \%$ até uma vez por semana e 3\% responderam não ter acessado nas últimas semanas. No polo 2, 36,4\% disseram ter acessado de duas a três vezes por semana; $28,8 \%$ até uma vez por semana; $15,2 \%$ mais de três vezes por semana, e 19,6\% responderam não ter acessado nas últimas semanas. No que se refere à quantidade de horas destinadas ao curso, no que tange ao polo 1, a maioria, 54,4\% responderam dedicar até 2 horas semanais; 36,4\% de 2 a 4 horas e 9,2\% mais de 4 horas. Já no polo 2, 71,2\% responderam dedicar até 2 horas semanais; $27,3 \%$ de 2 a 4 horas e $1,5 \%$ mais de 4 horas. 
Os achados deste estudo corroboram com os resultados da pesquisa realizada por Cavalcante e Santos Jr (2013), com 56 estudantes de um curso técnico a distância em Porto Alegre (RS), no ano de 2011, onde o tempo de dedicação dos estudantes foi de duas a três horas para 48\%, uma hora para 23\%, de quatro a cinco horas, para 13\%; de seis a dez horas, para $11 \%$ e mais de 10 horas, para $5 \%$. Mediante um comparativo entre os dois estudos, percebeu-se que em ambos os cursos técnicos o tempo de dedicação aos cursos é baixo, o que justifica a necessidade de uma maior participação por parte dos estudantes.

A queda no acesso às disciplinas e ao curso de uma forma ampla direciona a uma possível evasão escolar. Nesta perspectiva, Lacerda e Espíndola (2013) argumentaram que a evasão geralmente acontece no primeiro semestre em cursos a distância; sendo assim, o contato inicial, na maioria das vezes, é decisivo para a permanência do estudante. Em sua análise em um curso de licenciatura EAD de Nova Friburgo (RJ), os autores demonstraram um índice de evasão de 45,3\% no curso em questão por meio de uma análise documental.

Os percentuais revelaram que poucos estudantes disseram não ter acessado os curso/disciplinas nas últimas semanas ( 23 de março até 6 de abril), totalizando um quantitativo de 15 estudantes (considerando-se o polo 1 e o 2) levando-se em consideração a esfera de 132 participantes. Os resultados demonstraram uma contradição em um comparativo aos relatórios gerados no AVA do Moodle, e que também podem ser evidenciados a partir das respostas no Gráfico 1 abaixo, no que concerne aos motivos pelos quais não têm acessado ao curso/disciplinas, que contou com um quantitativo de 82 respostas (considerando-se o polo 1 e o 2 ).

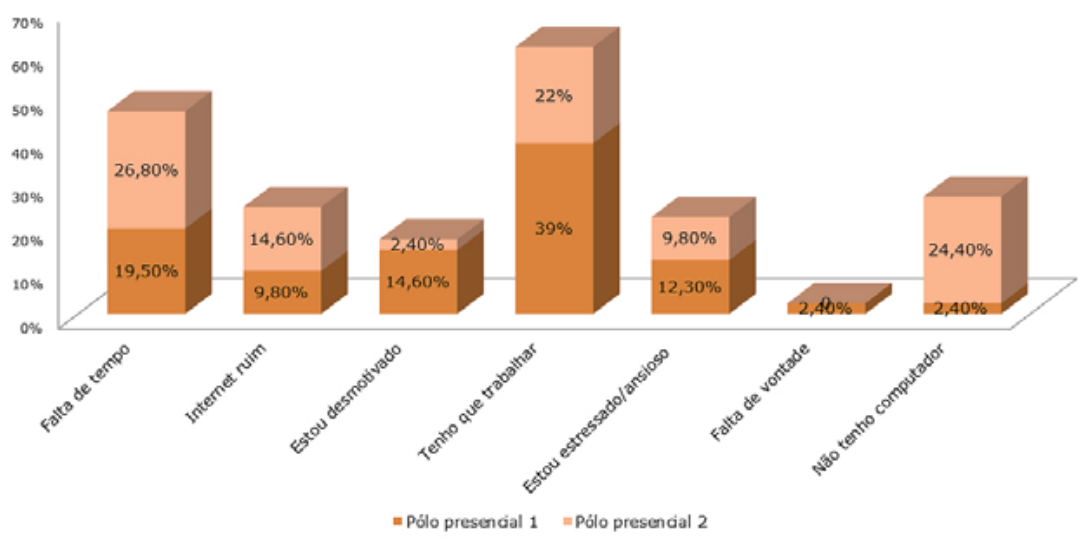

Gráfico 1: Motivo pelo qual não têm acessado o curso/disciplina nas últimas semanas.

A dificuldade em conciliar trabalho e curso faz parte do cotidiano do estudante de um curso a distância (LACERDA, ESPÍNDOLA, 2013). É pertinente argumentar que, apesar de um total de 22,9\% dos estudantes ter mencionado não ter acessado o curso nas últimas semanas, o que totalizou 15 estudantes nos dois polos, no que tange aos motivos pelos quais não têm acessado, 82 estudantes (considerando-se o polo 1 e 2) responderam à questão, o que efetivamente aproxima-se da realidade demonstrada pelos relatórios que direcionaram as constantes quedas de acessos após a suspensão de atividades presenciais e fechamento dos polos.

Dentre os principais motivos pelos quais os estudantes do polo 1 não têm acessado o curso e as disciplinas, destacaram-se "tenho que trabalhar, não estou conseguindo" para 39\%; "falta de tempo" para 19,5\%; "estou estressado/ansioso com esta situação de pandemia" para 12,3\%; "estou desmotivado" para 14,6\%; "internet ruim" para 9,8\%; "falta de vontade" para 2,4\% e "não tenho computador" para 2,4\%. Para os estudantes do polo 2, os principais motivos foram a "falta de tempo" para 26,8\%; "não tenho computador" para 24,4\%; "tenho que trabalhar, não estou conseguindo", para 22\%; "internet ruim" para 14,6\%; "estou estressado/ansioso com esta situação de pandemia" para 9,8\% e "estou desmotivado" para 2,4\%. 
Os resultados corroboraram com os achados de Lacerda e Espíndola (2013), em que os autores demonstraram que, dentre os principais motivos decisivos na evasão escolar para os 30 ex-alunos do curso de licenciatura estavam relacionados problemas pessoais, para 17\%; dificuldade em conciliar o trabalho com o curso, para 10\%; entre outros aspectos, e com a pesquisa realizada por Thiago, Carvalho e Trigueiro (2020), em que os autores apontaram como elementos direcionadores à evasão escolar em um curso de bacharelado, a dificuldade em conciliar o curso com outras atividades e a falta de tempo.

Diante desses aspectos, salienta-se a essencialidade de haver uma rotina de estudos para dedicação aos afazeres específicos que o curso demanda. Apesar de o curso ser flexível, para que não aconteça o acúmulo de conteúdos e atividades, orienta-se ao seguimento de um cronograma e à organização diária e acompanhamento das disciplinas.

No quadro atual, pensando-se na constante instabilidade gerada pela pandemia COVID-19, que, de certa forma, tem alterado a dinâmica de trabalho, rotina, e estudos, gerando, por vezes, medo, tensão, estresse, ansiedade e insegurança (SPONCHIATO, 2020), buscou-se descobrir se a situação de pandemia tem alterado/afetado o desempenho escolar dos estudantes.

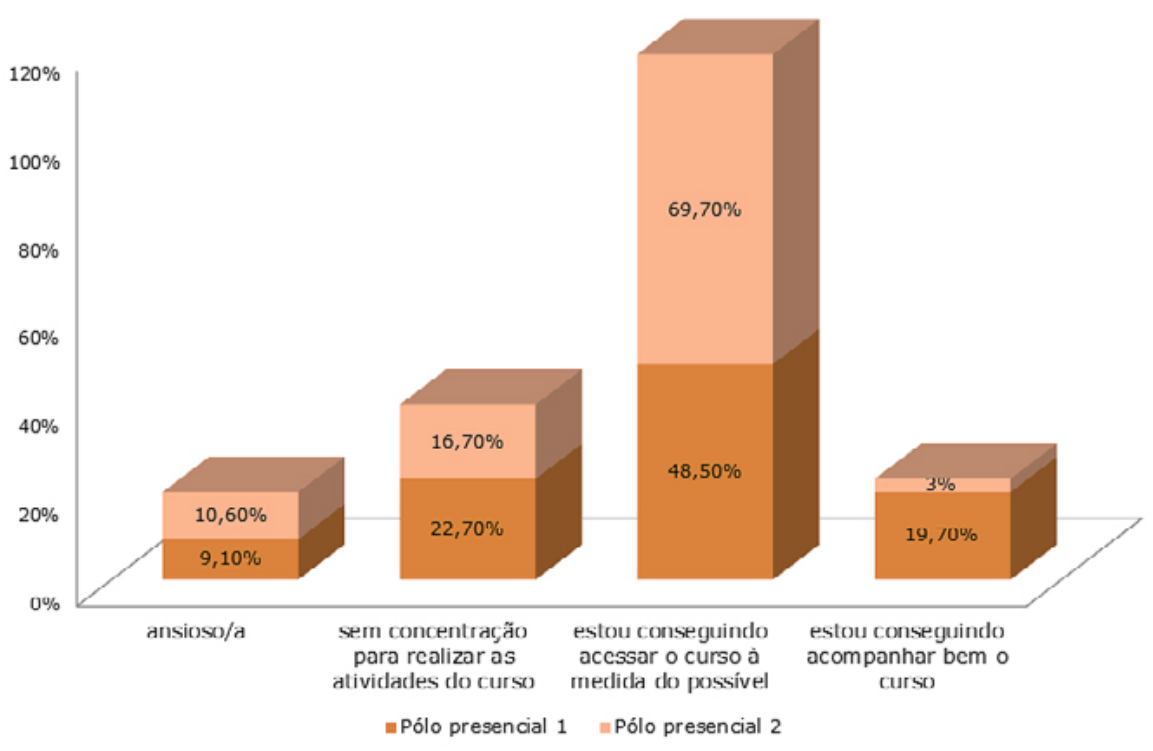

Gráfico 2: Como se sente atualmente

Tal como apresentado no Gráfico 2, a maioria dos estudantes disse estar conseguindo acessar e acompanhar o curso, 68,2\% (polo presencial 1), e 72,7\% (polo presencial 2). No entanto, um elemento que direcionou a uma maior atenção é um percentual significativo de estudantes que se consideraram sem concentração para realizar as atividades do curso, 22,7\% (polo 1) e 16,7\% (polo 2), além de estarem se sentindo ansiosos, 9,10\% (polo1) e 10,6\% (polo2), o que vem ao encontro dos resultados apresentados por uma pesquisa junto a 4693 pessoas no Brasil, e que demonstrou que "mais da metade dos participantes se diz extremamente preocupada com a COVID-19 no Brasil" (SPONCHIATO, 2020, s/p.).

Vários fatores influenciam o desempenho escolar, estando, pois, relacionados à infraestrutura, corpo docente, biblioteca, coordenação de curso, bem como auxílio constante de tutores (CAVALCANTE; SANTOS JR, 2013). No Gráfico 3, a seguir, é apresentada a percepção dos estudantes sobre a influência da COVID-19 em seu desempenho escolar. 


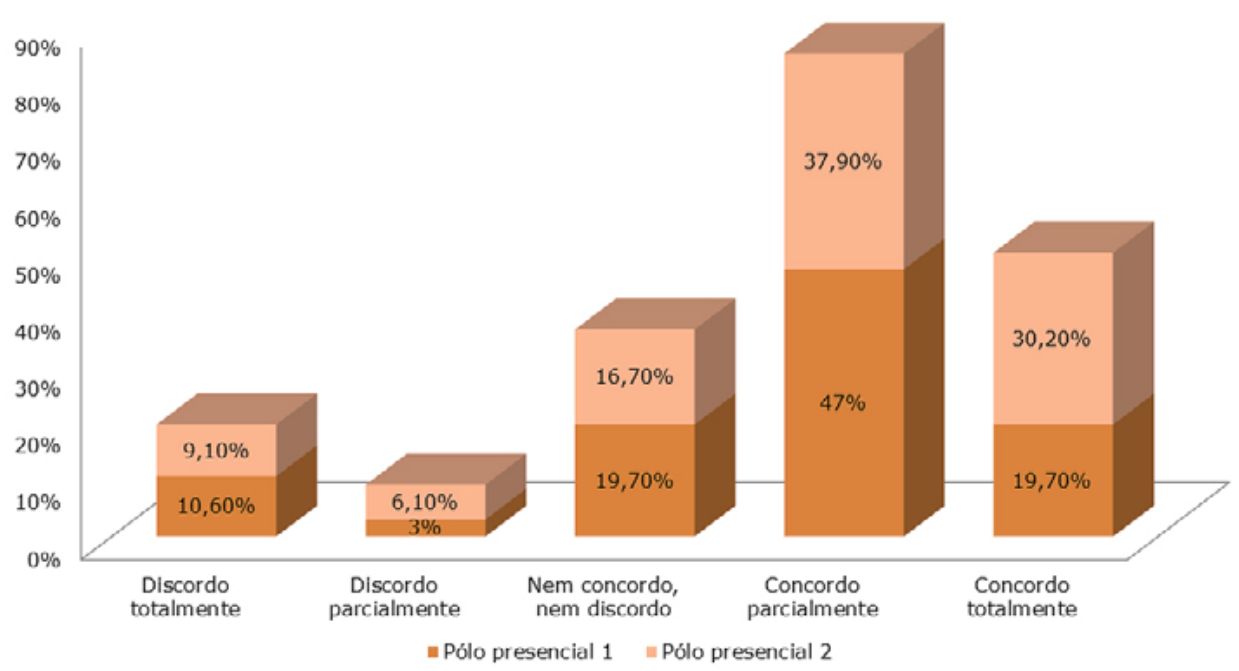

Gráfico 3: Influência do COVID-19 no desempenho escolar

Apesar de alguns estudantes terem mencionado não estarem sentindo a influência do distanciamento social e da pandemia COVID-19, para 13,6\% (polo 1) e 15,2\% (polo 2), os resultados apontaram uma forte influência desta situação em seu desempenho escolar, que pode ser confirmada pelo somatório das três últimas opções (nem concordo/nem discordo, concordo parcialmente e concordo totalmente), para 86,4\% (polo 1) e para $84,8 \%$ (polo 2 ) dos estudantes.

Os achados podem ser discutidos com os resultados de Cavalcante e Santos Jr (2013), ao identificarem os principais fatores que influenciaram o desempenho escolar de estudantes de um curso técnico em Contabilidade em Porto Alegre (RS). Os resultados apontados pelos autores demonstraram que, por trás do desempenho dos estudantes, estão implícitos tanto fatores externos quanto internos ao curso.

Outro aspecto diz respeito ao fechamento do polo de apoio presencial, onde muitos estudantes tinham o suporte e as ferramentas (computador e acesso à internet) para realizarem suas atividades. Frente à falta de suporte e auxílio por parte de tutores e da infraestrutura disponibilizada nos polos de apoio empresarial, os estudantes, por vezes, acabam se sentindo sozinhos e desassistidos.

O diagnóstico apontou forte influência do distanciamento social, suspensão de atividades presenciais, fechamento de polos de apoio presencial, falta de recursos essenciais para acesso ao curso (computador/ internet) no desempenho escolar dos estudantes. Essas informações direcionam a uma possível evasão escolar. Diante de tais aspectos, ações institucionais devem ser pensadas.

\section{Conclusões}

A partir deste diagnóstico, que tornou possível identificar os principais desafios enfrentados por estudantes de um curso técnico à distância, auferiu-se que o desempenho escolar está sendo fortemente comprometido mediante a situação de distanciamento social devido à pandemia COVID-19, principalmente após o fechamento dos polos de apoio presencial.

A queda de acessos averiguada pelos relatórios no AVA, bem como o pouco tempo destinado às demandas das disciplinas aliado aos baixos acessos semanais e baixa participação, revelaram uma grande possibilidade de evasão escolar. No mais, fatores como desemprego e exclusão digital para alguns estudantes demonstraram a inviabilidade de continuar o curso sem o auxílio do polo de apoio presencial, vista a situação de vulnerabilidade social e econômica em que muitos se encontram. 
Os resultados apontaram que os estudantes do polo 2 foram os mais prejudicados diante desta situação, visto que um percentual significativo não possui computador nem acesso à internet, e costumava realizar as atividades com o suporte e apoio de tutores/as no polo de apoio presencial. Diante desses resultados, destaca-se a essencialidade do apoio de tutores/as e da infraestrutura disponibilizada pelos polos de apoio presencial para a efetividade de um curso a distância.

Frente a essa situação, buscando-se estimular o distanciamento social e a segurança dos professores, estudantes e tutores, ações estão sendo realizadas pela coordenação de curso e direção de ensino, de forma a auxiliar os estudantes em situação de vulnerabilidade econômica e social, por meio da possibilidade de um auxílio inclusão digital e de empréstimos de computadores, enquanto perdurar a situação de pandemia.

Assim, salienta-se sobre a riqueza ferramental disponibilizada pelo AVA no Moodle, por meio da possibilidade de emissão de relatórios, enquanto diagnóstico para a tomada de decisões, evitar ou minimizar a evasão escolar, e pensar estrategicamente mudanças e aperfeiçoamento metodológico-didático para as disciplinas e curso.

O estudo restringiu-se a identificar os desafios dos estudantes frente à pandemia COVID-19 nos dois polos de apoio presencial, sem uma análise mais apurada de suas percepções sobre as disciplinas, metodologia e avaliação do curso. Desta forma, sugere-se, para a realização de pesquisas futuras, estudos voltados à percepção dos estudantes sobre seu desempenho e comprometimento em relação ao curso.

Espera-se que este estudo, enquanto diagnóstico de gestão, possa auxiliar coordenadores e gestores na tomada de decisões a partir da elaboração de diagnósticos voltados ao planejamento de ações para os cursos a distância.

\section{Referências}

ASSOCIAÇÃO BRASILEIRA DE INTERNET (ABRANET). Desafio da internet é levar conexão a quem ainda não tem no Brasil. 2019. Disponível em:<http://www.abranet.org.br/Noticias/Desafio-da-internet-e-levar-conexao-a-quem-ainda-nao-tem-no-Brasil-2384.html?UserActiveTemplate=site\#.Xs774DpKjlU>. Acesso em 27 de maio de 2020.

BRASIL. Decreto No. 9.057, de 25 de maio de 2017. Regulamenta o Art. 80 da Lei N. 9.394, de 20 de dezembro de 1996, que estabelece as diretrizes e bases da educação nacional. Brasília, 2017.

CARNEIRO, M. L. F. Instrumentalização para o ensino a distância. Planejamento e Gestão para o Desenvolvimento Rural da SEAD/UFRGS. Porto Alegre: Editora da UFRGS, 2009.

CAVALCANTE, C. H. L.; SANTOS JUNIOR, P. A. Fatores que influenciam o desempenho escolar: a percepção dos estudantes do Curso Técnico em Contabilidade do IFRS. Revista Liberato. Novo Hamburgo, v. 14, n. 21, 2013.

CLARO, M. Tipos de Relatórios no Moodle. 2014. Disponível em:<https://www.moodlelivre.com.br/tutoriais-e-dicas/potal/tutoriais-e-dicas-moodle/tipos-de-relatorios-no-moodle>. Acesso em 15 de abril de 2020.

CROKIDAKIS, N. Data analysis and modeling of the evolution of COVID-19 in Brazil. arXiv: 2003.12150 [q-bio.PE], 2020.

ESTRELA, C. Metodologia científica: ciência, ensino, pesquisa [recurso eletrônico]. 3. ed. Porto Alegre: Artes Médicas, 2018. 
FARIAS, F. R.; DIAS, M. J. Os desafios entre o ensino presencial e o ensino a distância: uma questão de cultura digital e de formação do educador. Revista Científica em Educação a Distância EAD em FOCO. v.1, n.1. Rio de Janeiro, 2010.

FERREIRA, V. H.; SILVA, J. M. C. Relatórios: saiba tudo o que os seus alunos fizeram. In: SILVA, J. M. C. (ORG.) Moodle para Professores. Instituto Federal Rio Grande Do Sul - Campus Bento Gonçalves, 2017.

FREITAS, A. R. R.; NAPIMOGA, M.; DONALISIO, M. R. Análise da gravidade da pandemia de COVID-19. Epidemiologia e Serviços de Saúde. v. 29, n.2. Brasília, 2020.

GIL, A. C. Como elaborar projetos de pesquisa. 6ed. São Paulo: Atlas, 2018.

INSTITUTO FEDERAL FARROUPILHA (IFFar). Instrução Normativa $\mathbf{N}^{\circ} \mathbf{0 3 / 2 0 1 8}$. Dispõe sobre a oferta de cursos na modalidade de Educação a Distância (EaD) de forma Institucionalizada no âmbito do Instituto Federal de Educação, Ciência e Tecnologia Farroupilha (IFFar). Santa Maria, 2018.

LACERDA, F. K. D. de; ESPÍNDOLA, R. de M. Evasão na educação a distância: um estudo de caso. Revista Científica em Educação a Distância EAD em FOCO. Fundação Cecierj. v.3, n.1, 2013.

MINISTÉRIO DA EDUCAÇÃO (MEC). Resolução $\mathbf{N}^{\circ} \mathbf{6}$, de 20 de setembro de 2012. Define Diretrizes Curriculares Nacionais para a Educação Profissional Técnica de Nível Médio. Brasília, 2012.

MINISTÉRIO DA EDUCAÇÃO (MEC). Portaria N³43, de 17 de março de 2020. Dispõe sobre a substituição das aulas presenciais por aulas em meios digitais enquanto durar a situação de pandemia do Novo Coronavírus - COVID-19. Brasília, 2020a.

MINISTÉRIO DA EDUCAÇÃO (MEC). Portaria N 345, de 19 de março de 2020. Altera a Portaria $\mathrm{MEC} \mathrm{N}^{\circ}$ 343, de 17 de março de 2020. Disponível em:<http://pesquisa.in.gov.br/imprensa/jsp/visualiza/index. jsp?jornal=603\&pagina=1\&data=19/03/2020\&totalArquivos=1>. Acesso em 29 de abril de 2020. 2020 b.

MINISTÉRIO DA CIDADANIA/SECRETARIA ESPECIAL DO DESENVOLVIMENTO SOCIAL/SECRETARIA NACIONAL DE ASSISTÊNCIA SOCIAL. Portaria N 54, de $\mathbf{1}^{\circ}$ de abril de 2020. Brasília, 2020.

SPONCHIATO, D. Pesquisa mostra o grau de medo e tensão dos brasileiros com o coronavírus. Disponível em:<https://saude.abril.com.br/mente-saudavel/medo-e-tensao-brasileiros-coronavirus/>.Acesso em 15 de abril de 2020 .

PALLOF, R. M.; PRATT, K. O aluno virtual: um guia para trabalhar com estudantes on-line. Tradução de Vinícius Figueira. Porto Alegre: Artmed, 2004.

SANTOS, P. K. dos; GIRAFFA, L. M. M. Permanência na graduação a distância na perspectiva dos Estudantes: um estudo a partir da experiência do projeto Alfa. Congresso CLABES VI, 2016.

SOUZA, J. B. A. de S. A contribuição dos polos presenciais na EaD: um estudo exploratório. Congresso Nacional de Ambientes (CONAHPA). São Luís, MA, 2015.

SILVA, D. G. Análise sobre o uso dos relatórios de atividades do Moodle no acompanhamento do processo de aprendizagem de alunos em cursos de graduação. Dissertação de Mestrado. Programa de Pós-Graduação em Educação. Universidade Federal de Mato Grosso, 2011.

TENÓRIO, A. et al. Ferramentas da educação a distância: a visão do tutor Revista Científica em Educação a Distância EAD em FOCO.v.4,n.1. Rio de Janeiro, 2014.

TENÓRIO, T.; RODRIGUES, F. A.; TENÓRIO, A. Estudo de caso sobre o uso das ferramentas notas e relatórios do Moodle na prática pedagógica do tutor à distância em cursos brasileiros de formação continuada de professores. Revista Científica em Educação a Distância- EAD em FOCO. v.6,n.2, 2016. 
THIAGO, F.; CARVALHO, J. C., TRIGUEIRO, F. M. C. Fatores de Evasão na Educação à Distância: Um estudo no Curso de Bacharelado em Administração Pública. Revista Científica em Educação a Distância EAD em FOCO. v.1, 2020.

UMEKAWA, E. E. Preditores de fatores relacionados à evasão e a persistência discente em ações educacionais a distância. Dissertação de Mestrado. Departamento de Psicologia, Universidade de São Paulo/USP, Ribeirão Preto, 2014.

XAVIER, M. A. G. A Gestão Pública do Sistema da Universidade Aberta do Brasil: estudo de caso no polo de apoio presencial em Resende. Revista Científica em Educação a Distância-EAD em FOCO. v. 6, n. 1, 2016. 